\title{
Info Energy and Stem Cells Medicine
}

\author{
Maria Kuman* \\ Holistic Research Institute, USA
}

Submission: May 25, 218; Published: May 30, 2018

*Corresponding author: Maria Kuman, Holistic Research Institute, 1414 Barcelona Dr., Knoxville, TN 37923, USA,

Email: holisticare@mariakuman.com

Abstract

If we want to be considered advanced civilization, we shouldn't consider ourselves as a bag with chemicals interacting in a certain fat-ion, but we should consider ourselves intelligent beings endowed with mind and emotions. This article proves with measurements that not only do emotions play essential role in our health and wellbeing, our way of thinking plays essential role. Positive thinking increases our energy and makes us healthier, which means you need to be happy to be healthy. Opposite to this, negative thinking decreases our energy and the genetically inherited weak organ drops in energy maximum. This means that each negative thought takes us a step farther to a disease of the genetically weak organ. If so, our medicine needs to consider the role, which our emotions and ways of thinking play in our health. Emotions, way of thinking, and mind are indelible part of our nonlinear electromagnetic field (NEMF). As intelligent beings, we should understand that there are two ways to influence humans to restore their health: one is by influencing the chemical reactions in the body (which we do with the help of pharmaceutical industry) and the other is by influencing our NEMF, which is the Info Energy Medicine or Quantum Medicine. They should have equal right of existence. Special attention is devoted to the stem cells used in combination with the Info Energy Medicine.

Keywords: Info energy medicine; Positive thinking and health; Positive emotions and health; Negative thinking and disease; Negative emotions and disease; Stem cells and info energy medicine

\section{Introduction}

The germs, we are trying to kill, adapt fast to the existing drugs. We need to find new stronger pharmaceutical drugs to kill them. In the last 10 years, $40 \%$ of the pharmaceutical drugs were new. The new drugs are more powerful and have more side effects. Studies in Switzerland showed that more than $70 \%$ of the drugs have side effects. Thus, in the fight with the germs our body always looses. There are germs already resistant to all existing drugs. Something needs to be done. There are two ways to restore our health: one is by restoring the chemical balance of the body (what we are doing now with our pharmaceutical drugs) and the other way is by restoring the missing electromagnetic waves of our nonlinear electromagnetic field (NEMF), which rules and regulates all the chemical processes in the body. When the chemical drugs stop working, we need to be ready to switch to a different way of healing.

\section{Measuring the human NEMF in two different ways}

The author of this article measured the electrical component of the human NEMF with her patented sensitive equipment capable of measuring one millionth of ampere and less. The results can be seen on Figure 1. Positive thinking (upper curves) was found to increase the energy of our NEMF and makes it more balanced, which means that happy thoughts make us healthier [1]. On the vertical axis is the measured electrical component of the human NEMF [in microamperes] of different individuals when thinking about the happiest moment of their life (upper curve) and when thinking about the saddest moment of their life (lower curve). On the horizontal axis are the points of measurements - the energy centers, which are alternating vortices and antivortices of the human nonlinear electromagnetic field (NEMF), which has the shape of a torus (Figure 2). 


\section{Current Trends in Biomedical Engineering \& Biosciences}
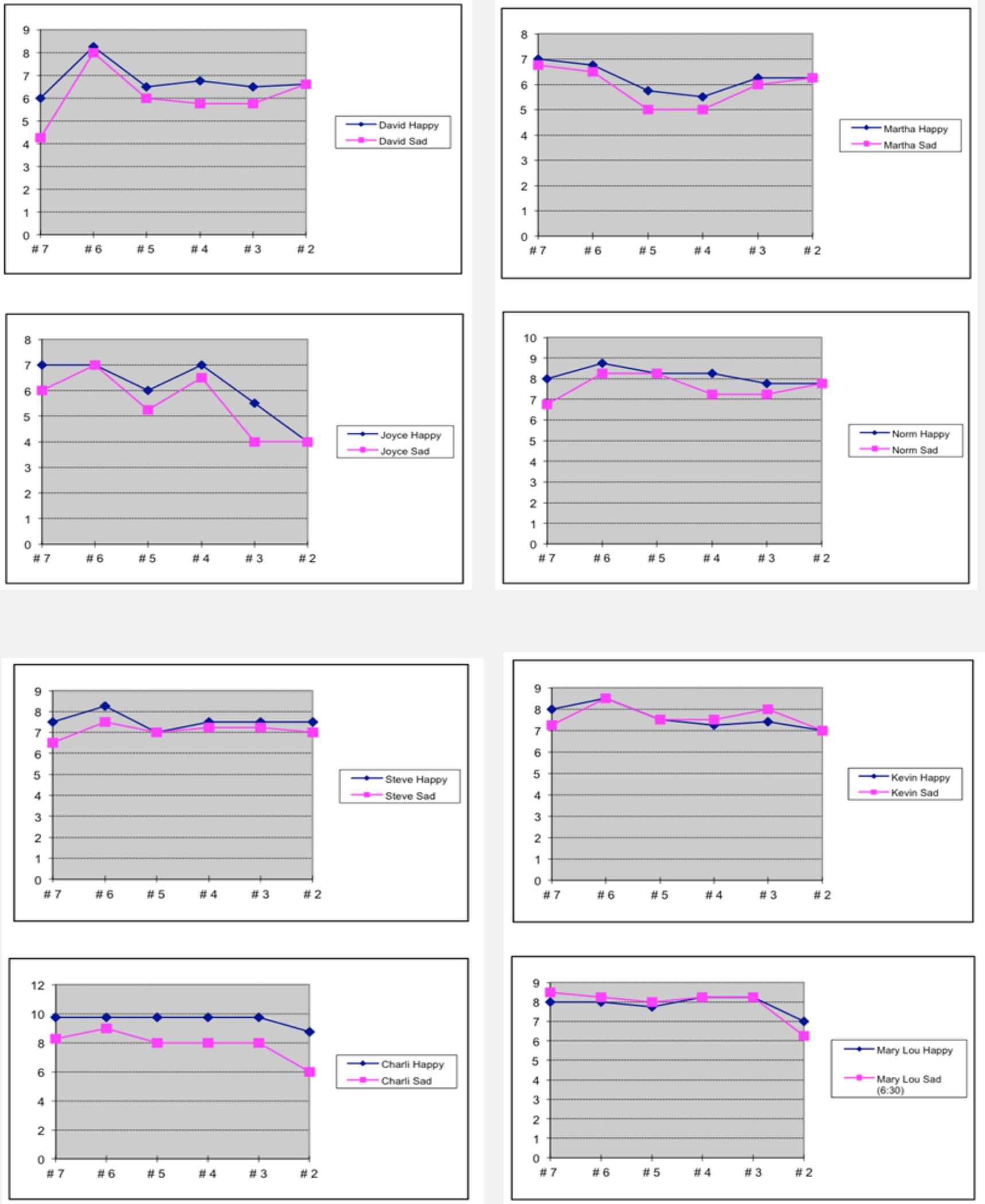

Figure 1: 


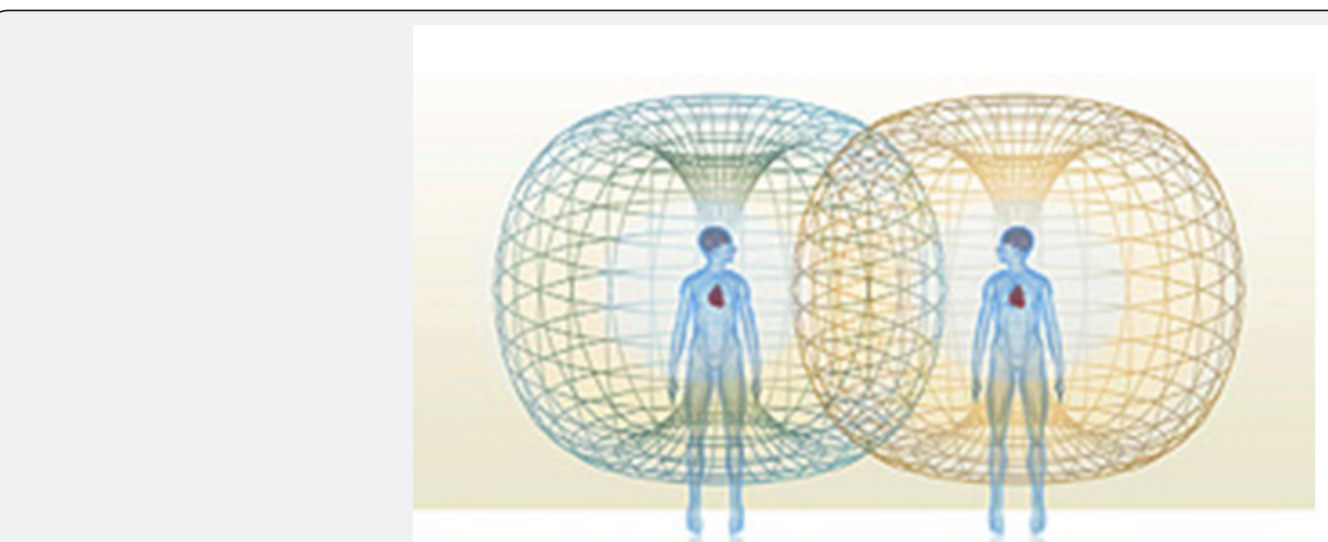

Figure 2: Human Nonlinear Electromagnetic Field (NEMF) (Adopted from the webpage of the HearthMath Institute).

Negative thinking (lower curves) was found to have just the opposite effect - it decreases the energy and makes it more unbalanced because the genetically inherited weak organ drops in energy maximum. This means that each unhappy (negative) thought take us a step farther to a disease of the genetically inherited weak organ [1]. The Russian scientist Shkatov patented equipment that allows him to measure the spinning of the human donut shaped NEMF (Figure 1). He found that positive emotions make the donut shaped NEMF spin faster clockwise [2]. Since according to nonlinear physics vortices spin clockwise and suck energy, at positive emotions (or just positive thinking) our clockwise spinning NEMF must suck energy or gain energy. This agrees fully with our findings that positive thinking (or emotions) increases the energy of our NEMF [3].

Another set of measurements of Reiki healers with our sensitive equipment showed that their claim that they use Universal energy to heal (Rei-Ki means Universal Energy) is right [4]. The measured energy on top of their heads was higher after each treatment. For this to happen, they must suck electrical energy from the atmosphere through the upper hole of their donut shaped NEMF, which according to nonlinear physics must spin clockwise for this to happen. Thus, clockwise spinning of our donut shaped NEMF increases its energy because energy is sucked in through the clockwise spinning vortex at the hole of the donut. Such sucking of energy through the hole of the donut was observed between two binary stars, which have the same donut shaped NEMF. The dimmer star sucks energy from the brighter star through the hole of its donut shaped NEMF until their brightness become equal [5-7].

Shkatov found with his patented equipment that negative emotions make the human NEMF spin faster counterclockwise. Since according to nonlinear physics anti-vortices spin counterclockwise and emit energy, at negative emotions (or just negative thinking) our counterclockwise spinning NEMF must emit energy or loose energy. This agrees fully with our findings that negative thinking (or emotions) decrease the energy of our NEMF. Our measurements show that at negative emotions (or just negative thinking), not only does the human NEMF loses energy, the energy balance is lost because the genetically inherited weak organ drops in energy maximum, which takes us a step farther to a disease of this weak organ. Acad. Grabovoi of Russia generalized this in the following way: to stay healthy, we need to avoid negative information or to find ways to get rid of the damage of this negative information before it has sank at physical level [2] and made us sick.

\section{Developing the technology that would allow us to practice info energy medicine}

To be able to read information from our NEMF and to encode information on it, we need to create analog of our NEMF. Our NEMF is nonlinear as the name says. It is spinning. Its light is coherent (technically coherent light is the laser light). Its waves are also stationary. Through a reflexion of laser light from suitable mirrors, placed at right distances, the laser waves could be made stationary. Generator creating NEMF with such characteristics was created in Russia and it is known under the name "torsi-generator of Kozirev". The technology was developed in Hovosibirsk, Russia, and was successfully used for healing by influencing the NEMF, which rules and regulates all the processes in the body. The effect was instantaneous; the heath problem was resolved immediately. It could be used for any disease.

Also hypogeomagnetic cameras were created in Russia to read chromosome information and repair chromosome defects. It was used with success to correct genetic defects, such as children epilepsy, immune deficiency syndrome, etc. Reading the information from the chromosome of the mother and then transferring this information to the child did the necessary correction. Children with both types of genetic defects were successfully treated and they enjoyed normal healthy life.

\section{Info energy medicine combined with stem cells}

The torsion-generator of Kozirev was used to cure diseases with electromagnetic waves. When the torsion-generator was 
producing right-handed field spinning in clockwise direction, it was stimulating normal cell growth and division. When it was applied on malignant cells, in combination with stem cells, it was making the cancer cells normal. Dr. James Thompson from the University of Wisconsin in the US first drew attention to the unique properties of stem cells. In 1990, he was the first to insulate stem cells from four days human embryo. However, the social reaction in the US to the use of embryo cells for research or healing was strongly negative-it was considered unethical [2].

Alternative approaches almost immediately popped up. In the same year of 1990, Elian Gluckman in Paris did the first transplantation of stem cells from umbilical cord, while Prof. Werfel of the University of Minnesota first extracted stem cells from the bone marrow of rats. Just like the embryo stem cells, these stem cells could transform to any kind of cells - neuronal, muscular, cartilage, liver, brain, and etc. tissues

[2]. In 1994 the umbilical-cord method of Gluckman was successfully used in Prague on six-year old child diagnosed with immune deficiency syndrome. The stem cells from the umbilical cord of his newly born brother were used to correct his immune deficiency. He is healthy and ready to enjoy his life [2].

Now almost every country in Europe has such bank for stem cells from umbilical cords. Stored in liquid nitrogen they are good to be used for years on any member of the family. Japanese researchers from Tokyo University first were able to grow nerve and bone tissue from the cells of placenta. Compounds were found that could develop nerve or bone tissues from stem cells of placenta within 24 hours [2].

When stem cells from bone marrow were injected in the heart immediately after the heart attack, the recovery was complete. Research showed that after heart attack the bone marrow did produce stem cell for repair, but they reached the heart 6 days later and by that time the necrosis of heart cells has already taken place [2]. Some role probably played the fact that the blood was too thick, which caused the heart attack on the first place, and the tick slow-circulating blood could not provide on time the stem cells necessary for the repair of the heart damage.

Stem cells were also successfully used after strokes, and they didn't need to be injected in the brain, they went there and repaired the damage. Stem cells could also be used for repair of neurons damaged by brain disease or brain trauma. The wide specter of diseases that could be successfully treated with stem cells requested the creation of banks for stem cells in many countries [1]. Stem cells, when injected in the join or organ that needs repair, would restore the join or the organ by transforming into the type of cells needed for restoration of the join or organ. Russian scientists injected stem cells, where the Gall Bladder was surgically removed 13 years ago, and then projected the hologram of the Gall Bladder. After days the gall bladder regrew and it was like new [2].
In the US, the cytolog Ronald Mackey reported in the reputable journal Nature about successful use of stem cells on mice with inflicted Parkinson disease [2]. The diseases bare the name of Dr. J. Parkinson, who first described the symptoms of the disease in 1817: paralyses, pain, inability to move, walk, or talk caused by disturbed function of neurons in the brain [2]. In Israel, scientists from Wiseman Institute reported in journal Nature Medicine that they were able to successfully transplant human stem cells in mice. The stem cells grew into human kind of kidneys, which were functioning. When transplanted back into the human there was no rejection [2]. This could open a new page in the medicine of organ transplant.

\section{Conclusion}

Acad. Kaznacheev writes in his book: The Super Weak Emissions of the Intracellular Space: "Our research showed that electromagnetic fields play essential role in the transfer of biological information between the cells. It leads to the conclusion that the chemical mechanism of this connection is not primary, but result of more-complicated field interactions, which are the true carriers of information." In an Editorial article published in February of 2018 in: Advances in Complimentary and Alternative Medicine, I claim exactly this without knowing about the book of Kaznacheev. Negative stress, negative emotions, or just negative thoughts gobbles the energy of the nonlinear electromagnetic field (NEMF), which acts in the intracellular fluid and controls their division. When this NEMF is very weak, there is nothing to control the cellular growth and the cells start multiplying senselessly, which is the beginning of malignancy called cancer.

Thus, the information carried by our nonlinear electromagnetic field (NEMF) is essential for our health and wellbeing and we should make it the core of our medicine. Considering the importance of our NEMF in ruling and regulating everything in the body, we should make the use of electromagnetic waves for cure the backbone of our new Info Energy Medicine.

\section{References}

1. Kuman M (2015) Quantum mind and quantum growth. Health and Happiness Books, USA.

2. Tihoplav V, Tihoplav T (2003) Garmonia Haosa (The Harmony of the Chaos).

3. Kuman M (2017) Same fields and dynamics in stars and man. Heath and Happiness Books, USA.

4. Kuman M (2017) International Journal of Integrated Medicine 42(3-4).

5. Wheeler JC, Nance S, Diaz M, Smith SG, Hickey J, et al. (2017) The betelgeuse project: constraints from rotation. Monthly Notices of the Royal Astronomical Society 453(3): 2654-2661.

6. Burgay M, Amico ND, Possenti A, Manchester RN, Lyne AG, et al. (2004) An increased estimate of the merger rate of double neutron stars from observations of a highly relativistic system. Nature 426: 531-533.

7. Lyne AG, Burgay M, Kramer M, Possenti A, Manchester RN, et al. (2004) A double-pulsar system: a rare laboratory for relativistic gravity and plasma physics. Science 303(5661): 1153-1157. 
Your next submission with Juniper Publishers will reach you the below assets

- Quality Editorial service

- Swift Peer Review

- Reprints availability

- E-prints Service

- Manuscript Podcast for convenient understanding

- Global attainment for your research

- Manuscript accessibility in different formats

(Pdf, E-pub, Full Text, Audio)

- Unceasing customer service

Track the below URL for one-step submission https://juniperpublishers.com/online-submission.php 